\title{
Prevalence of seroprotection against the pandemic (H1N1) virus after the 2009 pandemic
}

\author{
Danuta M. Skowronski MD, Travis S. Hottes MSc, Naveed Z. Janjua MBBS DrPH, Dale Purych MD, \\ Suzana Sabaiduc BSc, Tracy Chan BSc, Gaston De Serres MD PhD, Jennifer Gardy PhD, \\ Janet E. McElhaney MD, David M. Patrick MD, Martin Petric PhD
}

Previously published at www.cmaj.ca

See also analysis article by Low and McGeer, page 1874

\section{ABSTRACT}

Background: Before pandemic (H1N1) 2009, less than $10 \%$ of serum samples collected from all age groups in the Lower Mainland of British Columbia, Canada, showed seroprotection against the pandemic (H1N1) 2009 virus, except those from very elderly people. We reassessed this profile of seroprotection by age in the same region six months after the fall 2009 pandemic and vaccination campaign.

Methods: We evaluated 100 anonymized serum samples per 10 -year age group based on convenience sampling. We measured levels of antibody against the pandemic virus by hemagglutination inhibition and microneutralization assays. We assessed geometric mean titres and the proportion of people with seroprotective antibody levels (hemagglutination inhibition titre $\geq 40$ ). We performed sensitivity analyses to evaluate titre thresholds of 80,20 and 10 .

Results: Serum samples from 1127 people aged 9 months to 101 years were obtained. The overall age-standardized proportion of people with seroprotective antibody levels was $46 \%$. A U-shaped age distribution was identified regardless of assay or titre threshold applied. Among those less than 20 years old and those 80 years and older, the prevalence of seroprotection was comparably high at about $70 \%$. Seroprotection was $44 \%$ among those aged 20-49 and 30\% among those $50-79$ years. It was lowest among people aged $70-79$ years $(21 \%)$ and highest among those 90 years and older (88\%).

Interpretation: We measured much higher levels of seroprotection after the 2009 pandemic compared than before the pandemic, with a U-shaped age distribution now evident. These findings, particularly the low levels of seroprotection among people aged $50-79$ years, should be confirmed in other settings and closer to the influenza season. $\mathrm{n}$ a previous age-based survey of about 1000 anony mized serum samples collected before substantial pandemic (H1N1) 2009 activity in the Lower Mainland of the province of British Columbia, Canada, we found that less than $10 \%$ of children and adults under 70 years of age had seroprotective levels of antibody against the pandemic (H1N1) virus. ${ }^{1}$ This proportion was slightly higher among people aged $70-79$ years (27\%) and substantially higher among those above 80 years of age $(77 \%){ }^{1}$

The 2009 influenza pandemic and the broad and effective vaccination campaign introduced major changes to this population's immune status. The first wave in the province, in the spring and summer months, was of limited activity and was followed by a second, more substantial and widespread wave in the fall that peaked during the last week of October and resolved by the end of 2009. ${ }^{2}$ Meanwhile, a highly immunogenic adjuvanted vaccine was provided free of charge through a universal vaccination campaign that targeted all Canadians. ${ }^{3}$ Supply was limited initially, requiring sequenced rollout of the vaccine, starting with children under five years of age, pregnant women, and people under 65 years who had comorbidities. ${ }^{4}$ The uptake of the vaccine of about $35 \%-45 \%$ in the province overall ${ }^{4-6}$ and $44 \%$ in the Lower Mainland (Dr. Monika Naus, BC Centre for Disease Control, Vancouver, BC: personal communication, 2010) was estimated to be moderate compared with rates of uptake in other provinces.

To assess seroprotective antibody levels after the 2009 pandemic, we repeated our age-based survey of antibody levels against the pandemic (H1N1) 2009 virus in a further 1000 serum samples collected from people in the Lower Mainland in May and June 2010, more than six months after the last peak of the epidemic.

\section{Methods}

Residual serum samples collected from patients who presented between May 8 and 21, 2010, were obtained from the central processing laboratory of a community laboratory net-

From the BC Centre for Disease Control (Skowronski, Hottes, Janjua Sabaiduc, Chan, Gardy, Patrick, Petric), Vancouver, BC; the School of Population and Public Health (Skowronski, Janjua, Patrick), and the Departments of Microbiology and Immunology (Gardy), Medicine (McElhaney) and Pathology and Laboratory Medicine (Petric), University of British Columbia, Vancouver, BC; BC Biomedical Laboratories Ltd. (Purych), Surrey, BC; Institut national de santé publique du Québec and Université Laval (De Serres), Québec, Que.; and the Vancouver Coastal Health Research Institute (McElhaney), Vancouver, BC

CMAJ 2010. DOI:10.1503/cmaj.100910 
work. The network has 45 patient service centres distributed across the Lower Mainland region of British Columbia. This region is the most densely populated, with 2.5 million of the province's 4.3 million people.?

Serum samples were collected at multiple community patient service centres across this region, with slight overrepresentation from municipalities of the Fraser Valley relative to the Vancouver metropolitan area. About 100 samples were assembled for each of the following age groups: $<5,5-9,10$ $19,20-29,30-39,40-49,50-59,60-69,70-79,80-89$ and $\geq 90$ years. To enable finer stratification in pediatric age groups, additional samples were collected between June 15 and 17, 2010, from children less than two years (7) and two to four years of age (20), which gave us totals of 26 and 100 serum samples in these two youngest age groups.

All of the samples were anonymized and provided without additional clinical detail (e.g., testing indication or vaccination history), such that individual consent was not required. The Clinical Research Ethics Board of the University of British Columbia approved the study.

The main outcome was the level of antibody against the pandemic (H1N1) 2009 virus, as measured by the hemagglutination inhibition assay and supplemented by the microneutralization assay. Both assays were performed at the BC Centre for Disease Control using a BC isolate of the influenza A/California/7/2009 virus per standard protocol (described in Appendix 1, available at www.cmaj.ca/cgi/content/full/cmaj $.100910 / \mathrm{DC} 1)$. Titres were summarized at the individual level as the geometric mean of duplicate inverse titres, with titres of less than 10 assigned a value of five. As previously defined, seroprotection was noted if the hemagglutination inhibition titre was 40 or higher. ${ }^{1.89}$ Geometric mean titres and the proportion of people with seroprotection, with Waldbased $95 \%$ confidence intervals, were summarized by age group. Sensitivity analyses included titre thresholds of 80,20 and 10. Direct standardization with 2010 population projections for the Lower Mainland region of the province generated an estimate of the overall age-standardized proportion of people who had seroprotection. ${ }^{\text {? }}$

\section{Results}

Serum samples collected from 1127 people (aged 9 months to 101 years) were included in our study (Table 1). Results of hemagglutination inhibition and microneutralization assays were well correlated (Pearson correlation coefficient 0.94), with little variation in coefficients by age group. Findings are summarized below based on the primary outcome of hemagglutination inhibition.

Overall, about half of the study population had seroprotective hemagglutination inhibition antibody levels to the pandemic (H1N1) 2009 virus in May and June 2010 (agestandardized proportion: $46 \%$ [95\% CI 43\%-50\%] by hemagglutination inhibition assay and $41 \%$ [95\% CI 38\%44\%] by microneutralization assay). The geometric mean titres and proportion of people with seroprotection against the pandemic virus showed a U-shaped distribution by age group regardless of the assay used (Table 1, Figure 1). Whereas seroprotection was high among people less than 20 years of age $(70 \%, 95 \%$ CI $65 \%-75 \%)$, it was significantly lower among adults $20-49$ years $(44 \%, 95 \%$ CI $39 \%-50 \%)$ and lower still among those $50-79$ years $(30 \%, 95 \%$ CI $25 \%-$

Table 1: Results of serologic testing for antibodies against the pandemic (H1N1) virus, as measured by hemagglutination inhibition and microneutralization assays, among 1127 people in Lower Mainland, British Columbia, six months after the 2009 pandemic

\begin{tabular}{|c|c|c|c|c|c|c|c|}
\hline \multirow[b]{2}{*}{$\begin{array}{l}\text { Age } \\
\text { group, yr }\end{array}$} & \multirow[b]{2}{*}{$\begin{array}{l}\text { No. of } \\
\text { patients }\end{array}$} & \multirow[b]{2}{*}{$\begin{array}{l}\text { Median } \\
\text { age, yr }\end{array}$} & \multirow[b]{2}{*}{$\begin{array}{l}\text { Female } \\
\text { sex, } \%\end{array}$} & \multicolumn{2}{|c|}{ Hemagglutination inhibition assay } & \multicolumn{2}{|c|}{ Microneutralization assay } \\
\hline & & & & $\begin{array}{l}\text { Geometric mean titre } \\
\qquad(95 \% \mathrm{Cl})\end{array}$ & $\begin{array}{c}\% \text { with titre } \geq 40 \\
(95 \% \mathrm{Cl})\end{array}$ & $\begin{array}{l}\text { Geometric mean titre } \\
\qquad(95 \% \mathrm{Cl})\end{array}$ & $\begin{array}{c}\% \text { titre } \geq 40 \\
(95 \% \mathrm{Cl})\end{array}$ \\
\hline$<2^{*}$ & 26 & 1 & 54 & $147.7 \quad(58.4-373.6)$ & $69(50-88)$ & $211.7(75.7-592.2)$ & $69(50-88)$ \\
\hline $2-4$ & 100 & 3 & 43 & $88.8 \quad(60.3-130.7)$ & $69(60-78)$ & $124.7(78.9-196.9)$ & $65(55-75)$ \\
\hline $5-9$ & 98 & 7 & 50 & $73.0 \quad(52.5-101.5)$ & $71(62-81)$ & $83.2(56.4-122.8)$ & $62(52-72)$ \\
\hline $20-29$ & 100 & 26 & 73 & $24.8 \quad(18.4-33.4)$ & $44(34-54)$ & $29.4(21.2-40.7)$ & $37(27-47)$ \\
\hline $30-39$ & 100 & 35 & 65 & $29.8(21.5-41.3)$ & $46(36-56)$ & $37.8(26.3-54.5)$ & $41(31-51)$ \\
\hline $40-49$ & 100 & 45 & 59 & $24.6 \quad(17.7-34.2)$ & $43(33-53)$ & $30.8(21.1-45.1)$ & $41(31-51)$ \\
\hline $50-59$ & 100 & 54 & 59 & $15.1 \quad(11.6-19.5)$ & $30(21-39)$ & $20.8(15.9-27.3)$ & $29(20-38)$ \\
\hline $60-69$ & 100 & 64 & 46 & $21.1 \quad(16.1-27.8)$ & $38(28-48)$ & $22.9(17.6-29.9)$ & $27(18-36)$ \\
\hline All & 1127 & 44 & 56 & $38.5 \quad(34.8-42.5)$ & $46(43-50) \ddagger$ & 44.5 (39.8-49.7) & 41 (38-44)‡ \\
\hline
\end{tabular}

Note: $\mathrm{Cl}=$ confidence interval.

*Actual age span 9 months to $<2$ years.

tActual age span 90 to 101 years.

$\ddagger$ Overall seroprotection ( $\%$ with titre $\geq 40$ ) age-standardized to Lower Mainland, BC population. 
$35 \%)$. The lowest level of seroprotection was observed among people $70-79$ years of age (21\%, 95\% CI 13\%-29\%). Seroprotection was significantly higher among people 80 years and older $(69 \%, 95 \%$ CI $62 \%-74 \%)$ : it was $42 \%(95 \%$ CI 30\%-54\%) among those 80-84 years, 67\% (95\% CI 47\%$84 \%$ ) among those $85-89$ years and $88 \%$ (95\% CI 82\%-94\%) among those 90 years of age and older.

The sensitivity analyses showed similar U-shaped distributions by age in the proportion of people meeting or exceeding titre thresholds of 80,20 or 10 (Appendix 2, available at www.cmaj.ca/cgi/content/full/cmaj.100910/DC1). Among the age groups with the lowest levels of seroprotection, the proportion with hemagglutination inhibition titres of 10 or higher was $57 \%$ of those aged $50-59$ years, $71 \%$ of those $60-69$ years and $69 \%$ of those $70-79$ years. The corresponding proportions with microneutralization titres of 10 or higher were $71 \%, 82 \%$ and $66 \%$ in these three age groups. However, these findings represented mostly low-level antibody detection, because the proportion of people with titres of 20 or higher was lower in the same age groups (hemagglutination assay: $40 \%$ of those aged $50-59$ years, $50 \%$ of those $60-69$ years and $42 \%$ of those $70-79$; microneutralization assay: $43 \%$ of those aged $50-59$ years, $50 \%$ of those $60-69$ years and $26 \%$ of those 70-79). As in the primary analysis, the proportion of people with titres of at least 80 was highest among those less than 20 years old and among those 90 years of age and older; it was lowest among those 50-79 years old. The overall agestandardized proportion with a titre of at least 80 was $25 \%$ (95\% CI 22\%-28\%) by hemagglutination inhibition assay and $29 \%$ (95\% CI 26\%-32\%) by microneutralization assay.

\section{Interpretation}

In this follow-up study, conducted more than six months after the fall 2009 pandemic and vaccination campaign, we found a different U-shaped distribution of seroprotection by age group compared with our findings in the same region before these events. ${ }^{1}$ The substantial increase in seroprotection we observed in the young groups may have resulted from higher attack rates of pandemic (H1N1) influenza ${ }^{4,10-14}$ and earlier prioritization of vaccination among young children. ${ }^{4,6}$ In the Lower Mainland region of British Columbia, a telephone survey showed that the profile of pandemic (H1N1) vaccine coverage by age also followed a U-shaped distribution, being highest among children less than 10 years old and people 65 years and older (57\% in each group), but lower among school-aged children $10-19$ years old (37\%), adults 20-49 years old (38\%) and adults 50-64 years old (47\%) (Dr. Monika Naus: personal communication, 2010). Rates of pandemic (H1N1) influenza were reported to have been highest among school-aged children, ${ }^{4,10-14}$ which likely contributed to higher seroprotection despite lower vaccine coverage among those 10-19 years old.

The people who had the lowest rate of seroprotection (titre $\geq 40$ ) after the 2009 pandemic were those 50-79 years old. Of note, the levels of seroprotection among those 70-79 did not change measurably after the pandemic (hemagglutination inhibition assay: $27 \%$ before and $21 \%$ after the pandemic; microneutralization assay: $6 \%$ before and $13 \%$ after the pandemic). ${ }^{1}$ These low levels after the pandemic, despite substantial vaccine coverage (about $60 \%$ ) in this age group, warrant further investigation because it may signal aberrant responses

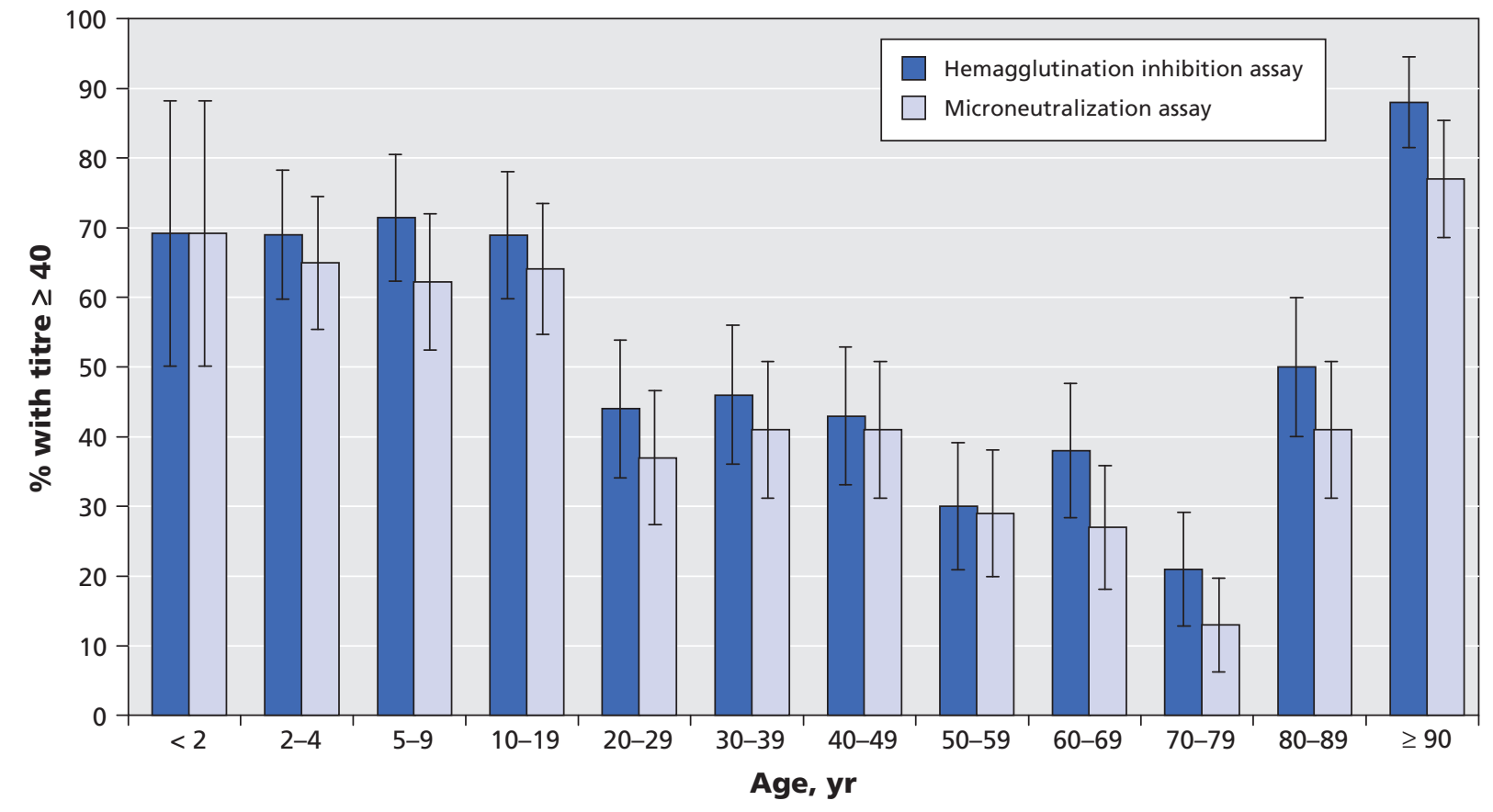

Figure 1: Proportion of 1127 people in the Lower Mainland of British Columbia who had an antibody titre of 40 or higher (by hemagglutination inhibition and microneutralization assays) against the pandemic (H1N1) virus six months after the 2009 pandemic, by age group. 
to the vaccine. People 70-79 years of age were reported to have had the lowest seropositivity rate in a similar serologic survey conducted in mid-November and early December 2009 among residents in Pittsburgh, Pennsylvania. ${ }^{14}$ A discrepancy between estimates of postpandemic seroprotection and adjuvanted pandemic (H1N1) vaccine coverage among adults aged 50-79 years was also noted in at least one other serologic survey in Norway. ${ }^{15}$

At a population level, the critical fraction of immunity required to prevent sustained transmission is related to a pathogen's reproductive number $\left(R_{o}\right)$, expressed as $1-1 / R_{o}$. Lower estimates of $R_{o}$ imply lower levels of immunity required to prevent an epidemic. Various estimates of $R_{o}$ have been derived for the pandemic (H1N1) virus, ranging up to 3.0 in the setting of a school outbreak, but are generally between 1.5 and 2.0 on average..$^{16-20}$

On that basis, community-level protection against the pandemic (H1N1) virus in the range of 33\%-50\% overall would be enough to prevent an epidemic, assuming random mixing of people of different ages and homogeneous immunity. School-aged children, however, are thought to contribute disproportionately to influenza transmission. ${ }^{21}$ Our study identified seroprotection estimates of $46 \%$ overall by hemagglutination inhibition assay ( $41 \%$ by microneutralization assay) and $70 \%$ (64\% by microneutralization assay) among schoolaged children.

In combination, these findings reassure against the likelihood of a substantial third wave of pandemic (H1N1) during the 2010/11 influenza season, unless there is substantial waning of antibody levels or a change in the virus. Such drift has not occurred to date in the dominant circulating pandemic (H1N1) strain but may be considered a future likelihood. Until then, sporadic cases or limited pockets of activity will likely occur, but the high attack rates of pandemic (H1N1) influenza observed in 2009, especially among children, now appear improbable in the Lower Mainland region of British Columbia for the coming season.

As in previous pandemics, surveillance reports of pandemic (H1N1) 2009 consistently showed that incidence rates were highest among young people, whereas the risk of death from the disease was highest among elderly people. ${ }^{4,22-29} \mathrm{~A}$ high incidence of infection among young people, multiplied by even a small likelihood of death, can still result in more pediatric deaths, as evident in the 2009 pandemic. A shift in the age distribution back toward a more typical seasonal pattern of disproportionate burden of severe disease in older groups has generally taken several years to occur following other pandemics. ${ }^{22}$ In the absence of vaccination, this shift occurs gradually as young people accumulate infectioninduced immunity over successive epidemics and their influenza attack rates diminish. The results of our study suggest that high levels of immunity against pandemic (H1N1) influenza among young people were achieved much more quickly — within a year of the 2009 pandemic. This rapid change occurred probably because a massive pandemic vaccination campaign with highly immunogenic adjuvanted vaccine supplemented the population immunity induced by the high pandemic attack rates. As a result, the high attack rates that contributed to severe outcomes among young people during the 2009 pandemic are unlikely to recur during the 2010/11 influenza season.

Conversely, adults aged 50-79 years had lower seroprotection against the pandemic virus while remaining at intrinsically higher risk of severe illness and death if infected. In that context, a shift in disease burden back toward older adults accounting for a greater proportion of severe outcomes may come about more rapidly than was observed with previous pandemics. A demographic shift in disease burden toward adults generally next season has been proposed in recent mathematical models from Canada and the United States..$^{30}$

For the coming 2010/11 influenza season, the World Health Organization has recommended that the pandemic (H1N1) virus be included in the seasonal trivalent influenza vaccine. More active targeting of this trivalent vaccine to people 50 years and older for the coming influenza season, particularly those with comorbidities, could provide protection against severe outcomes due not only to pandemic (H1N1) influenza but also to seasonal influenza.

\section{Limitations}

There are several caveats to the interpretation of our results. We dichotomized hemagglutination inhibition titres at 40 because this cut-off is the conventional $50 \%$ seroprotective threshold routinely applied to seasonal influenza and to vaccine approval. ${ }^{8,9}$ However, this threshold has not been validated specifically for the pandemic (H1N1) virus or all age groups. We measured higher proportions but the same Ushaped distribution by age group for antibody titres exceeding lower thresholds of 10 or 20. Lower thresholds are of uncertain clinical significance but may signal virus exposure contributing to other forms of protection (e.g., heterologous cellmediated immunity). In general, however, higher influenza antibody titres signal higher likelihood of protection, so that the similar age-related pattern observed at thresholds of 40 or 80 are likely to be more meaningful. ${ }^{8,9}$

For efficiency, we used convenience sampling of about 100 anonymized residual serum samples per 10-year age group collected from patients who presented for other clinical testing. We did not have additional details about their comorbidities or vaccination history. We cannot readily interpret age-related seroprotection more finely than the per decade sampling we conducted, and further evaluation of more discrete ages may be warranted. Also, convenience sampling may have led to an overestimate of seroprotection. Patients having blood drawn for a clinical indication may have a greater prevalence of underlying conditions or health care behaviours associated with a higher likelihood of receiving the pandemic (H1N1) vaccine. However, this influence on our findings was unlikely to be strong, because the estimated seroprotection was lowest among people aged 50-79 years, among whom chronic comorbidities become increasingly prevalent. Conversely, unmeasured comorbidities conferring immunosuppression could have resulted in underestimation of the true proportion considered to have seroprotection.

For comparative purposes, we restricted our study to the 
same region in which we had conducted our previous serologic survey. ${ }^{1}$ However, different people in the region were included in each study, and thus seroconversion cannot be directly computed. Seroprotection may be lower in less densely populated areas where attack rates were lower or in places where a less immunogenic vaccine was used or where lower vaccine coverage was achieved. British Columbia reported moderate vaccine coverage overall, which suggests that levels of seroprotection may be even higher in provinces with greater vaccine coverage..$^{4-6} \mathrm{~A}$ vaccination registry did not exist in British Columbia to enable precise estimation of age-specific uptake of the pandemic (H1N1) vaccine. We were unable to assess directly the proportion of people whose seroprotection was attributed to infection rather than to vaccination. Nonetheless, it is reassuring that, in most age groups for which vaccination data were available, our estimates of seroprotection approximated or exceeded the measured vaccine coverage cited above. However, vaccine coverage in the Lower Mainland region was nearly $60 \%$ among people 65 years and older (Dr. Monika Naus: personal communication, 2010). As such, we would have expected to find a higher proportion of elderly people up to 79 years of age with seroprotective titres. Response to vaccine may vary by age, although clinical trials have shown that the adjuvanted vaccine used in Canada induced high antibody titres, exceeding typical seasonal vaccine responses, with seroprotection rates of more than $90 \%$ in all age groups assessed, including people over 60 years old. ${ }^{3}$

We measured antibody levels more than six months after the vaccination campaign. Over that prolonged interval, estimates of seroprotection, although high in younger groups, may have waned from an earlier peak. Our estimates from samples collected in May and June 2010 may not absolutely reflect seroprotection for the upcoming 2010/11 influenza season, but age-related comparisons should be robust because the rate of decline of influenza antibody levels is not considered to be strongly influenced by age. ${ }^{31}$

\section{Conclusion}

Our estimates of seroprotection against pandemic (H1N1) influenza in the Lower Mainland of British Columbia were dramatically different from levels measured in the same region before the fall 2009 pandemic wave and vaccination campaign. These estimates likely preclude a third pandemic wave for the coming 2010/11 influenza season, unless there is substantial waning of immunity or a change in the virus. People 50-79 years old had low levels of seroprotection while remaining at higher risk of severe illness and death if infected. Our findings support a shift from prioritized vaccination of young people that occurred in fall 2009 to prioritized vaccination of older adults for the coming 2010/11 influenza season. Given the implications, our estimates of seroprotection should be assessed in other settings and closer to the influenza season.

\section{This article has been peer reviewed.}

Competing interests: Danuta Skowronski was the principal investigator for an unrelated clinical trial for which influenza vaccine was provided free by
Sanofi Pasteur. Gaston De Serres received research grants from GlaxoSmithKline and Sanofi Pasteur for research on hepatitis B and pertussis. Jennifer Gardy received travel assistance from Genome British Columbia to attend a conference on the control of influenza. Janet McElhaney has participated on advisory boards for GlaxoSmithKline, Sanofi Pasteur and MedImmune and on the data monitoring board for Sanofi Pasteur; she has received research grants from the Canadian Institutes of Health Research, the US National Institute of Allergy and Infectious Diseases and GlaxoSmithKline, has participated in clinical trials sponsored by Merck, GlaxoSmithKline and Sanofi Pasteur and has received honoraria for presentations sponsored by Merck, GlaxoSmithKline and Sanofi Pasteur. No competing interests declared by Travis Hottes, Naveed Janjua, Dale Purych, Suzana Sabaiduc, Tracy Chan, David Patrick or Martin Petric.

Contributors: Danuta Skowronski, Travis Hottes, Naveed Janjua, Dale Purych, Gaston De Serres, Janet McElhaney and David Patrick designed the study. Danuta Skowronski, Travis Hottes, Naveed Janjua and Dale Purych oversaw the data collection. Suzana Sabaiduc, Tracy Chan and Martin Petric oversaw and performed the laboratory testing. Jennifer Gardy oversaw virus sequencing analysis and interpretation. Travis Hottes and Naveed Janjua analyzed the data. Danuta Skowronski, Travis Hottes, Naveed Janjua and Gaston De Serres guided the analysis. All of the authors had access to the data (including statistical reports and tables) and take responsibility for the study. All of the authors contributed to the writing of the manuscript and approved the final version submitted for publication.

Acknowledgements: The authors gratefully acknowledge Leslie Love for coordination assistance with this project, Hochan Kim of the Genome Research Laboratory at the BC Centre for Disease Control for assistance with virus sequencing and interpretation, and local health care providers and public health practitioners for their invaluable contribution to pandemic (H1N1) surveillance activities.

Funding: Funding for this study was provided by the Michael Smith Foundation for Health Research (grant no. OT-GIA-00012091). The funding organization did not have a role in the study design, the collection and analysis of data, the decision to publish or the preparation of the manuscript.

\section{REFERENCES}

1. Skowronski DM, Hottes TS, McElhaney J, et al. Immuno-epidemiologic correlates of pandemic H1N1 surveillance observations: higher antibody and lower cellmediated immune responses with advanced age. J Infect Dis. In press.

2. BC Centre for Disease Control. BC Influenza Surveillance Bulletins: 2009-2010. Vancouver (BC): The Centre; 2010. Available: www.bccdc.ca/dis-cond/Disease StatsReports/influSurveillanceReports.htm (accessed 2010 Oct. 3).

3. Arepanrix H1N1. Mississauga (ON): GlaxoSmithKline Inc.; 2010. Available: www.gsk.ca/english/docs-pdf/Arepanrix_2010.pdf (accessed 2010 June 28).

4. BC's response to the H1N1 pandemic: a summary report June 2010. Victoria (BC): BC Office of the Provincial Health Officer; 2010. Available: www.hls.gov.bc.ca/pho /pdf/PHO_Report_BC_Response_to_the_H1N1_Pandemic_June2010.pdf (accessed 2010 Aug. 20).

5. Alphonso C. The flu reality: Ottawa's mass immunization program failed. Globe and Mail [Toronto] 2010 June 3;A:1

6. Canadian community health survey: H1N1 vaccinations. Ottawa $(\mathrm{ON})$ : Statistics Canada; 2010. Available: www.statcan.gc.ca/daily-quotidien/100719/dq100719beng.htm (accessed 2010 Oct. 3)

7. Population estimates (1986-2008) and projections (2009-2036). P.E.O.P.L.E. 34 (July 1): 2009-2036. Victoria (BC): BC Ministry of Citizens' Services; 2010.

8. Committee for Proprietary Medicinal Products [CPMP]. Note for guidance on harmonization of requirements for influenza vaccines. London (UK): European Agency for the Evaluation of Medicinal Products; 1997 CPMP/BWP/214/96 (circular no. 96-0666):1-22. Available: www.emea.europa.eu/pdfs/human/bwp/021496en.pdf (accessed 2010 June 28).

9. Potter CW, Oxford JS. Determinants of immunity to influenza infection in man. $\mathrm{Br}$ Med Bull 1979;35:69-75.

10. Miller E, Hoschler K, Hardelid P, et al. Incidence of 2009 pandemic influenza A H1N1 infection in England: a cross-sectional serological survey. Lancet 2010;375:1100-8.

11. Updated CDC estimates of $2009 \mathrm{H} 1 \mathrm{N1}$ influenza cases, hospitalizations and deaths in the United States, April 2009 - April 10, 2010. Atlanta (GA): US Centers for Disease Control and Prevention; 2010. Available: www.cdc.gov/h1n1flu /estimates 2009 h1n1.htm (accessed 2010 June 28).

12. Environmental Science and Research. Seroprevalence of the 2009 influenza A (H1N1) pandemic in New Zealand. Wellington (New Zealand): New Zealand Ministry of Health; 2010. Available: www.moh.govt.nz/moh.nsf/pagesmh/10124/\$File /seroprevalence-flu-2009.pdf (accessed 2010 June 28).

13. Gilbert GL, Cretikos MA, Hueston L, et al. H1N1 2009 antibodies in residents of New South Wales, Australia, after the first pandemic wave in the 2009 southern hemisphere winter. PLoS One 2010;9:e12562.

14. Zimmer SM, Crevar CJ, Carter DM, et al. Seroprevalence following the second 


\section{HYDROMORPH Contin'q12h}

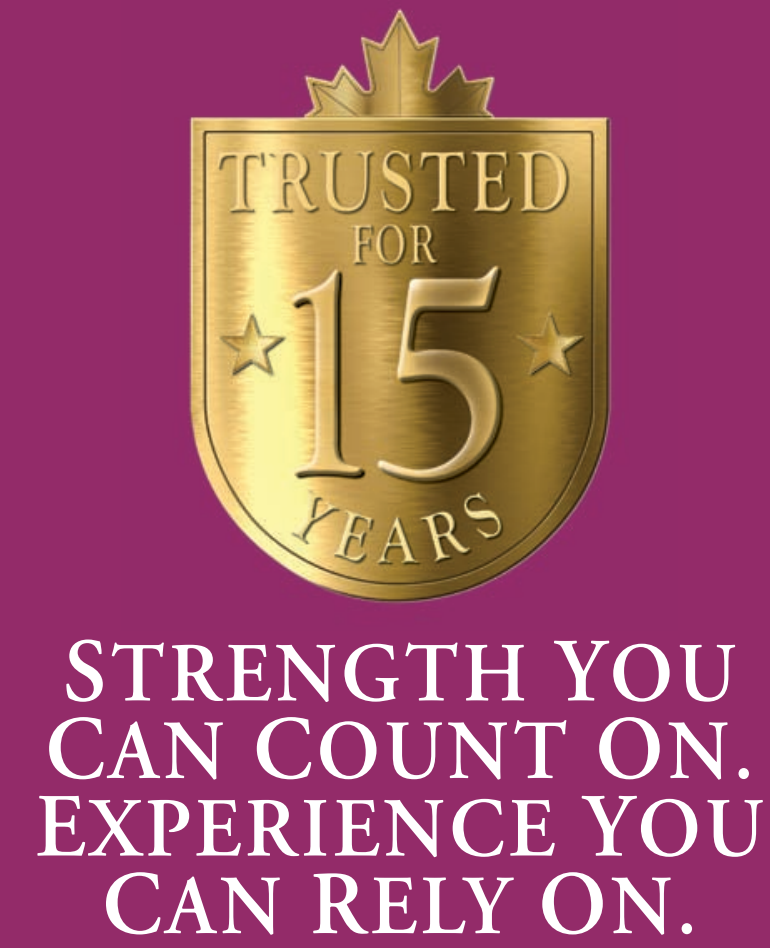

Hydromorph Contin ${ }^{\circledast}$ is indicated for the relief of severe chronic pain requiring the prolonged use of an oral opioid preparation.

Side effects are similar to other opioid analgesics. The most frequently observed are asthenic conditions, confusion, constipation, dizziness, lightheadedness, nausea, sedation, sweating and vomiting. Dosage limitations may be imposed by adverse effect. If they occur, please refer to prescribing information. Warning: Opioid analgesics should be prescribed and handled with a high degree of caution appropriate to the use of a drug with strong abuse potential. Patients should be cautioned not to consume alcohol while taking Hydromorph Contin ${ }^{\circledR}$, as it may increase the chance of experiencing dangerous side effects. Hydromorph Contin ${ }^{\circledR} 18 \mathrm{mg}$ capsules and higher are for use in opioid tolerant patients only. There is a potential for fatal respiratory depression in patients not previously exposed to similar equianalgesic doses of an opioid analgesic. Hydromorph Contin ${ }^{\circledR}$ capsules or capsule beads should not be chewed, crushed or dissolved since this can lead to rapid release and absorption of a potentially fatal dose of hydromorphone. Product monograph available on request. Hydromorph Contin ${ }^{\circledR}$ capsule beads may be sprinkled on cold, soft food.

\section{RESEARCH}

wave of pandemic 2009 H1N1 influenza in Pitttsburgh, PA, USA. PLoS ONE 2010;5:e11601

15. Waalen K, Kilander A, Dudman SG, et al. High prevalence of antibodies to the 2009 pandemic influenza $\mathrm{A}(\mathrm{H} 1 \mathrm{~N} 1)$ virus in the Norwegian population following a major epidemic and a large vaccination campaign in Autumn 2009. Euro Surveill 2010; 15:pii19633. Available: www.eurosurveillance.org/ViewArticle.aspx?ArticleId $=19633$ (accessed 2010 Oct. 3$)$.

16. Lessler J, Reich NG, Cummings DA, et al. Outbreak of 2009 pandemic influenza A (H1N1) at a New York City school. N Engl J Med 2009;361:2628-36.

17. Yang Y, Sugimoto JD, Halloran ME, et al. The transmissibility and control of pandemic influenza A (H1N1) virus. Science 2009;326:729-33.

18. Tuite AR, Greer AL, Whelan M, et al. Estimated epidemiologic parameters and morbidity associated with pandemic H1N1 influenza. CMAJ 2010;182:131-6.

19. White LF, Wallinga J, Finelli L, et al. Estimation of the reproductive number and the serial interval in early phase of the 2009 influenza A/H1N1 pandemic in the USA. Influenza Other Respi Viruses 2009;3:267-76.

20. Pourbohloul B, Ahued A, Davoudi B, et al. Initial human transmission dynamics of the pandemic (H1N1) 2009 virus in North America. Influenza Other Respi Viruses 2009;3:215-22.

21. Viboud C, Boëlle PY, Cauchemez S, et al. Risk factors of influenza transmission in households. Br J Gen Pract 2004;54:684-9.

22. Simonsen L, Clarke MJ, Schonberger LB, et al. Pandemic versus epidemic influenza mortality: a pattern of changing age distribution. J Infect Dis 1998;178:53-60.

23. Woodall J, Rowson KEK, McDonald JC. Age and Asian influenza, 1957. BMJ 1958;2:1316-8.

24. Collins SD. Age and sex incidence of influenza and pneumonia morbidity and mortality in the epidemic of 1928-29 with comparative data for the epidemic of 1918-19. Public Health Rep 1931;46:1909-36.

25. Baker MG, Wilson $\mathrm{N}$, Huang QS, et al, Pandemic influenza $\mathrm{A}(\mathrm{H} 1 \mathrm{~N} 1) \mathrm{v}$ in New Zealand: the experience from April to August 2009. Euro Surveill 2009;14:pii19319.

26. Donaldson LJ, Rutter PD, Ellis BM, et al. Mortality from pandemicA/H1N1 2009 influenza in England: public health surveillance study. BMJ 2009;339:b5213.

27. Louie JK, Acosta M, Winter K, et al. Factors associated with death or hospitalization due to pandemic 2009 influenza $\mathrm{A}(\mathrm{H} 1 \mathrm{~N} 1)$ infection in California. JAMA 2009:302:1896-902.

28. Vaillant L, La Ruche G, Tarantola A, et al. Epidemic intelligence team at InVS Epidemiology of fatal cases associated with pandemic H1N1 influenza 2009. Euro Surveill 2009;14:pii19309.

29. Campbell A, Rodin R, Kropp R, et al. Risk of severe outcomes among patients admitted to hospital with pandemic (H1N1) influenza. CMAJ 2010;182:349-55

30. Bansal S, Pourbohloul B, Hupert N, et al. The shifting demographic landscape of pandemic influenza. PLoS One 2010;5:e9360.

31. Skowronski DM, Tweed SA, De Serres G. Rapid decline of influenza vaccine-induced antibody in the elderly: Is it real, or is it relevant? J Infect Dis 2008;197:490-502.

Correspondence to: Dr. Danuta M Skowronski, BC Centre for Disease Control, 655 West 12th Ave., Vancouver BC V5Z 4R4; danuta.skowronski@bccdc.ca

\section{'HYDROMORPH Contin'q12h \\ Controlled release hydromorphone capsules}

A trusted choice for severe chronic pain

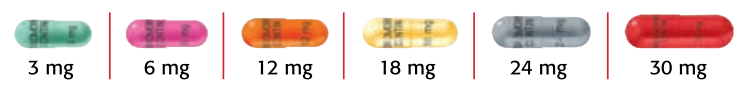

Initiation at $3 \mathrm{mg} \mathrm{q} 12 \mathrm{~h}$ or calculate the approximate daily oral hydromorphone dosage that should provide equivalent analgesia. See Product Monograph Table 1, Opioid Analgesics: Approximate Analgesic Equivalences.

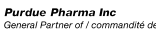

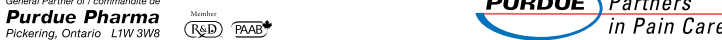

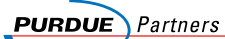

